\title{
ADAPTIVE TRANSMIT DIVERSITY SELECTION (ATDS) BASED ON STBC AND SFBC FIR 2X1 MIMO OFDM SYSTEMS
}

\author{
K. Vinod Babu ${ }^{1}$, G. Ramachandra Reddy ${ }^{2}$, Bala Krishna Nallagatla ${ }^{3}$, Bibin Baby John ${ }^{4}$, Suraj Gawande ${ }^{5}$
}

\begin{abstract}
In this paper, a new adaptive transmit diversity selection (ATDS) scheme is proposed for future wireless communication system to provide high spectral efficiency (SE) and good quality of service (QOS).The ATDS scheme selects the space time block code (STBC) orthogonal frequency division multiplexing (OFDM) scheme for flat fading channel and it selects space frequency block code (SFBC) OFDM scheme for frequency selective fading channel. The proposed scheme provides low average bit error rate (BER) and high average SE by using the benefits of STBC-OFDM for flat fading channel and SFBC-OFDM for frequency selective fading channel. The obtained simulation results validate this statement.
\end{abstract}

Keywords-ATDS, Channel Index (CI), STBC-OFDM, SFBC-OFDM

\section{INTRODUCTION}

The growing need for high rate spectrally efficient transmission has always forced researchers to come up with better transmission schemes. The flat fading and frequency selective fading caused by multipath effect is one major concern issue for future wireless communication systems. While flat fading causes signal deterioration and can be easily compensated, the Inter Symbol Interference (ISI) caused by frequency selective fading requires the need of complex equalizers at receiver side $[1,2]$. Multicarrier systems like OFDM can completely mitigate the effect of ISI using Cyclic Prefix (CP). This simple one tap equalization has made OFDM the favorite scheme for many $4 \mathrm{G}$ standards. It is used for various applications such as Digital Video Broadcasting (DVB), Digital Audio Broadcasting (DAB) and Asymmetric Digital Subscriber Line (ADSL) services. It can also be used for LTE, Wi-MAX based 4G systems [3].

Multi Input Multi Output (MIMO) systems were originally developed for flat fading channels. It offers spatial multiplexing as well as diversity gains which provides higher data rate and improved reliability respectively. In order to use the same concept in frequency selective channels, OFDM was used along with MIMO to convert the frequency selective channel to a number of flat fading channels. Transmit diversity and receive diversity are the two different diversities implemented in MIMO-OFDM systems [4, 5]. Transmit diversity is attractive for downlink purposes as more number of transmitting antennas can be used in the Base Station (BS). Transmit Diversity needs accurate channel information at the transmitter side it is not practically possible. STBC and Space Time Trellis Codes (STTC) are other transmit diversity schemes which work without the channel information at the transmitter side. In STTC, with the increase in number of states the complexity increases exponentially [3].
But both STTC and STBC are ideal only for flat fading channels. The major drawback of applying STBC for frequency selective fading channel is that fading destroys the orthogonality of STBC matrix. So it is preferred only for indoor environment and low data rate applications. MIMO equalizers are used with STBC systems for frequency selective fading channels. This again increases the complexity of the system. Hence a frequency diversity scheme, SFBC is employed for MIMO-OFDM to overcome frequency selective fading $[3,6]$.

In this paper, an adaptive transmit diversity selection scheme (ATDS) that uses the best of space diversity (MIMO), time diversity (STBC), frequency diversity (SFBC) and OFDM is proposed. Alamouti codes are used with STBC and SFBC to increase diversity gain $[2,5]$. The ATDS estimate the channel condition at the receiver and determines whether it is flat fading or frequency selective fading. The channel fading index $(\mathrm{CI}=0$ for flat fading and $\mathrm{CI}=1$ for frequency selective fading) is fed back to the transmitter. This helps in reducing the amount of feedback data and thus providing with better spectral efficiency. The transmitter then uses time diversity scheme for flat fading and frequency diversity scheme for frequency fading channels.

The rest of the paper is organized as followed. A brief explanation of STBC is given in section II. SFBC OFDM is discussed in section III. The proposed ATDS is explained in section IV. Section V contains simulation results and Section VI concludes the paper.

\section{STBC OFDM}

Space Time Block Code (STBC) is an efficient way to provide time diversity. The use of STBC along with MIMO OFDM offer simultaneous time and space diversity. The use of Alamouti code ensures orthogonality of the STBC matrix. A communication system with 2 transmitter antenna and 1 
receiver antenna is considered and hence STBC $2 \mathrm{X} 1$ block is considered [5].

The two OFDM symbols $\mathrm{x}_{1}(\mathrm{n})$ and $\mathrm{x}_{2}(\mathrm{n})$ are transmitted in two different time periods and through two different antennas, thereby providing both time and space diversity. For efficient implementation of STBC with $2 \times 1$ systems, the channel should be Quasi Static (QS) for two OFDM symbol periods [4]. The signal received at the receiver during the first and second symbol durations can be written as

$$
\begin{aligned}
& \mathrm{y}^{\mathrm{Ts}}(\mathrm{n})=\mathrm{h}^{1,1} \mathrm{x}_{1}(\mathrm{n})+\mathrm{h}^{1,2} \mathrm{x}_{2}(\mathrm{n})+\mathrm{w}^{\mathrm{Ts}}(\mathrm{n}) \\
& \mathrm{y}^{2 \mathrm{Ts}}(\mathrm{n})=-\mathrm{h}^{1,1} \mathrm{x}_{2}{ }^{*}(\mathrm{n})+\mathrm{h}^{1,2} \mathrm{x}_{1}{ }^{*}(\mathrm{n})+\mathrm{w}^{2 \mathrm{Ts}}(\mathrm{n})
\end{aligned}
$$

Where $\mathrm{n}=0,1,2, \ldots ., \mathrm{L}-1$.

Stacking (1) and conjugate of (2) in matrix form, we get

$$
\left(\begin{array}{c}
\mathrm{y}^{\mathrm{Ts}}(\mathrm{n}) \\
\mathrm{y}^{2 \mathrm{Ts}}(\mathrm{n})^{*}
\end{array}\right)=\left(\begin{array}{cc}
\mathrm{h}^{1,1} & \mathrm{~h}^{1,2} \\
\mathrm{~h}^{1,2^{*}} & -\mathrm{h}^{1,1^{*}}
\end{array}\right)\left(\begin{array}{c}
\mathrm{x}_{1}(\mathrm{n}) \\
\mathrm{x}_{2}(\mathrm{n})
\end{array}\right)+\left(\begin{array}{c}
\mathrm{w}^{\mathrm{Ts}}(\mathrm{n}) \\
\mathrm{w}^{2 \mathrm{Ts}}(\mathrm{n})^{*}
\end{array}\right)
$$

Let the weight matrix $\mathrm{S}$ be given as

$$
\begin{aligned}
& \mathrm{S}=\frac{1}{\|\mathrm{~h}\|}\left(\begin{array}{cc}
\mathrm{h}^{1,1} & \mathrm{~h}^{1,2} \\
\mathrm{~h}^{1,2^{*}} & -\mathrm{h}^{1,1^{*}}
\end{array}\right) \\
& \text { where }\|\mathrm{h}\|^{2}=\left|\mathrm{h}^{1,1}\right|^{2}+\left|\mathrm{h}^{1,2}\right|^{2}
\end{aligned}
$$

The detection of the transmitted OFDM symbols at the receiver can be done by the following procedure. Now multiplying (3) with $\mathrm{S}^{\mathrm{H}}$ on both sides,

$$
\left(\begin{array}{l}
\tilde{y}_{1}(n) \\
\tilde{y}_{2}(n)
\end{array}\right)=\left(\begin{array}{cc}
\|h\| & 0 \\
0 & \|h\|
\end{array}\right)\left(\begin{array}{l}
x_{1}(n) \\
x_{2}(n)
\end{array}\right)+\left(\begin{array}{l}
w_{1}(n) \\
w_{2}(n)
\end{array}\right)
$$

Where

$$
\begin{aligned}
& \tilde{\mathrm{y}}_{1}(\mathrm{n})=\frac{\mathrm{h}^{1,1} *}{\|\mathrm{~h}\|} \mathrm{y}^{\mathrm{Ts}}(\mathrm{n})+\frac{\mathrm{h}^{1,2}}{\|\mathrm{~h}\|} \mathrm{y}^{2 \mathrm{Ts}}(\mathrm{n}) \\
& \tilde{\mathrm{y}}_{2}(\mathrm{n})=\frac{\mathrm{h}^{1,2} *}{\|\mathrm{~h}\|} \mathrm{y}^{\mathrm{Ts}}(\mathrm{n})-\frac{\mathrm{h}^{1,1}}{\|\mathrm{~h}\|} \mathrm{y}^{2 \mathrm{Ts}}(\mathrm{n}) \\
& \mathrm{w}_{1}(\mathrm{n})=\frac{\mathrm{h}^{1,1} *}{\|\mathrm{~h}\|} \mathrm{w}^{\mathrm{Ts}}(\mathrm{n})+\frac{\mathrm{h}^{1,2}}{\|\mathrm{~h}\|} \mathrm{w}^{2 \mathrm{Ts}}(\mathrm{n})^{*} \\
& \mathrm{w}_{2}(\mathrm{n})=\frac{\mathrm{h}^{1,2} *}{\|\mathrm{~h}\|} \mathrm{w}^{\mathrm{Ts}}(\mathrm{n})-\frac{\mathrm{h}^{1,1}}{\|\mathrm{~h}\|} \mathrm{w}^{2 \mathrm{Ts}}(\mathrm{n})^{*}
\end{aligned}
$$

From (5)

$$
\begin{aligned}
& \tilde{y}_{1}(n)=\|h\| x_{1}(n)+w_{1}(n) \\
& \tilde{y}_{2}(n)=\|h\| x_{2}(n)+w_{2}(n)
\end{aligned}
$$

The transmitted two OFDM symbols can be detected from (7) with a simple Zero Forcing (ZF) equalization as

$$
\begin{aligned}
& \mathrm{x}_{1}(\mathrm{n})=\frac{\tilde{\mathrm{y}}_{1}(\mathrm{n})}{\|\mathrm{h}\|} \\
& \mathrm{x}_{2}(\mathrm{n})=\frac{\tilde{\mathrm{y}}_{2}(\mathrm{n})}{\|\mathrm{h}\|}
\end{aligned}
$$

In STBC with 2 Transmitting antennas and 1 receiving antenna, two OFDM symbols are transmitted in two OFDM symbol periods. It is a Rate 1 system [5]. The STBC system is suitable only for operation in flat fading channels. For frequency selective channels, we go for SFBC system.

\section{SFBC OFDM}

Space Frequency Block Codes (SFBC) can be considered as the counterpart of STBC which when used with MIMO system provide frequency diversity together with space diversity. As in the case with STBC, we use Alamouti codes for the purpose of orthogonality and consider the same communication system with 2 transmitter antenna and 1 receiver antenna that make use of $2 \mathrm{X} 1 \mathrm{SFBC}$ matrix which is given as[4,5]

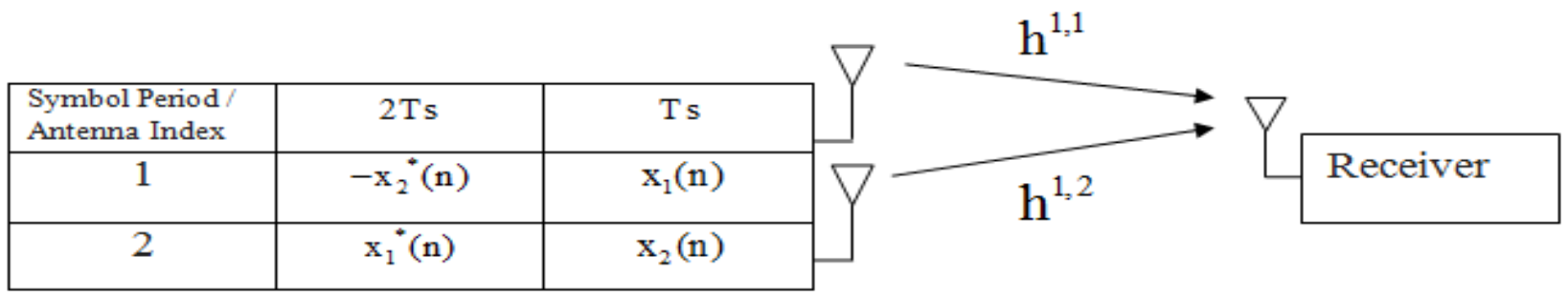

Fig 1: STBC 2X1 system using Alamouti Codes 


$$
D=\left[\begin{array}{cc}
X_{I}[2 m] & X_{I}[2 m+1] \\
-X_{I}[2 m+1]^{*} & X_{I}[2 m]^{*}
\end{array}\right]
$$

Where $\mathrm{m}=0,1 \ldots \frac{\mathrm{L}}{2}-1$

In (9), $X_{I}$ denote the M-QAM modulated symbols for the $1^{\text {th }}$ OFDM symbol and is given as

$$
X_{I}=\left[X_{I}[0], X_{I}[1], X_{I}[2] \ldots . . X_{I}[L-1]\right]^{T}
$$

The symbols coded in the first and second column of the matrix (9) are transmitted through first and second transmitting antennas respectively. The outputs obtained from each column is given for separate IFFT blocks and two different OFDM symbols are generated for the same set of L modulated symbols which is given by,

$$
\begin{aligned}
& \mathrm{x}_{\mathrm{I}}^{1,1}[\mathrm{n}]=\frac{1}{\mathrm{~L}} \sum_{\mathrm{m}=0}^{\mathrm{L}-1} \mathrm{X}_{\mathrm{I}}^{1,1}[\mathrm{~m}] \mathrm{e}^{\frac{\mathrm{j} 2 \pi \mathrm{mn}}{\mathrm{L}}} \\
& \mathrm{x}_{\mathrm{I}}^{1,2}[\mathrm{n}]=\frac{1}{\mathrm{~L}} \sum_{\mathrm{m}=0}^{\mathrm{L}-1} \mathrm{X}_{\mathrm{I}}^{1,2}[\mathrm{~m}] \mathrm{e}^{\frac{\mathrm{j} 2 \pi \mathrm{mn}}{\mathrm{L}}}
\end{aligned}
$$

where $\mathrm{n}=0,1 \ldots \ldots \mathrm{L}-1$

$\operatorname{In} \mathrm{X}_{\mathrm{I}}^{\mathrm{i}, \mathrm{j}}[\mathrm{n}]$, the superscript $\mathrm{i}, \mathrm{j}$ represents receiving and transmitting antenna indexes respectively. The signal received at the receiving antenna is given as

$$
y_{I}^{1}[n]=x_{I}^{1,1}[n] * h^{1,1}[n]+x_{I}^{1,2}[n] * h^{1,2}[n]+w_{I}^{1}[n]
$$

where $\mathrm{w}_{\mathrm{I}}^{1}[\mathrm{n}]$ is Additive White Gaussian Noise (AWGN). $\mathrm{h}^{1,1}[\mathrm{n}]$ and $\mathrm{h}^{1,2}[\mathrm{n}]$ are the fading channels corresponding to first and second transmitting antennas respectively. After L point FFT in the receiver,

$$
\mathrm{Y}_{\mathrm{I}}^{1}[\mathrm{~m}]=\mathrm{X}_{\mathrm{I}}^{1,1}[\mathrm{~m}] \mathrm{H}^{1,1}[\mathrm{~m}]+\mathrm{X}_{\mathrm{I}}^{1,2}[\mathrm{~m}] \mathrm{H}^{1,2}[\mathrm{~m}]+\mathrm{W}_{\mathrm{I}}^{1}[\mathrm{~m}]
$$

Where $\mathrm{m}=0,1, \ldots, \mathrm{L}-1$

The decoding of SFBC coded symbols in first two subcarriers is explained below. The same procedure is carried out to detect the symbols available in the rest of the subcarriers.

$$
\begin{aligned}
& Y_{I}^{1}[0]=X_{I}^{1,1}[0] H^{1,1}[0]+X_{I}^{1,2}[0] H^{1,2}[0]+W_{I}^{1}[0] \\
& Y_{I}^{1}[1]=X_{I}^{1,1}[1] H^{1,1}[1]+X_{I}^{1,2}[1] H^{1,2}[1]+W_{I}^{1}[1]
\end{aligned}
$$

As in the case with STBC, the quasi static condition must be satisfied for SFBC also. Hence the channels for two neighboring subcarriers are assumed to be constant [4].

$$
\begin{aligned}
& \mathrm{H}^{1,1}[0]=\mathrm{H}^{1,1}[1] \\
& \mathrm{H}^{1,2}[0]=\mathrm{H}^{1,2}[1]
\end{aligned}
$$

Substituting (15) in (14)

$$
\begin{array}{r}
Y_{I}^{1}[0]=X_{I}[0] H^{1,1}[0]+X_{I}[1] H^{1,2}[0]+W_{I}^{1}[0] \\
Y_{I}^{1}[1]=-X_{I}[1]^{*} H^{1,1}[0]+X_{I}[0]^{*} H^{1,2}[0]+W_{I}^{1}[1]
\end{array}
$$

Stacking (16) and conjugate form of (17) in matrix form as

$$
\left[\begin{array}{c}
\mathrm{Y}_{\mathrm{I}}^{1}[0] \\
\mathrm{Y}_{\mathrm{I}}^{1}[1]^{*}
\end{array}\right]=\left[\begin{array}{cc}
\mathrm{H}^{1,1}[0] & \mathrm{H}^{1,2}[0] \\
\mathrm{H}^{1,2}[0]^{*} & -\mathrm{H}^{1,1}[0]^{*}
\end{array}\right]\left[\begin{array}{c}
\mathrm{X}_{\mathrm{I}}[0] \\
\mathrm{X}_{\mathrm{I}}[1]
\end{array}\right]+\left[\begin{array}{c}
\mathrm{W}_{\mathrm{I}}^{1}[0] \\
\mathrm{W}_{\mathrm{I}}^{1}[1]^{*}
\end{array}\right]
$$

Let the weight matrix $\mathrm{S}$ be given as

$$
\begin{aligned}
& \mathrm{S}=\left[\begin{array}{ll}
\frac{\mathrm{H}^{1,1}[0]}{\|\mathrm{H}(0)\|} & \frac{\mathrm{H}^{1,2}[0]}{\|\mathrm{H}(0)\|} \\
\frac{\mathrm{H}^{1,2}[0]^{*}}{\|\mathrm{H}(0)\|} & \frac{-\mathrm{H}^{1,1}[0]^{*}}{\|\mathrm{H}(0)\|}
\end{array}\right] \\
& \text { where }\|\mathrm{H}(0)\|^{2}=\left|\mathrm{H}^{1,1}[0]\right|^{2}+\left|\mathrm{H}^{1,2}[0]\right|^{2}
\end{aligned}
$$

Multiplying both sides of (18) with $\mathrm{S}^{\mathrm{H}}$,

$$
\begin{aligned}
& \mathrm{Y}_{\mathrm{I}}[0]=\|\mathrm{H}[0]\| \mathrm{X}_{\mathrm{I}}[0]+\mathrm{W}_{\mathrm{I}}[0] \\
& \mathrm{Y}_{\mathrm{I}}[1]=\|\mathrm{H}[0]\| \mathrm{X}_{\mathrm{I}}[1]+\mathrm{W}_{\mathrm{I}}[1]
\end{aligned}
$$

Where

$$
\begin{gathered}
\mathrm{Y}_{\mathrm{I}}[0]=\frac{\mathrm{H}^{1,1}[0]^{*}}{\|\mathrm{H}(0)\|} \mathrm{Y}_{\mathrm{I}}^{1}[0]+\frac{\mathrm{H}^{1,2}[0]}{\|\mathrm{H}(0)\|} \mathrm{Y}_{\mathrm{I}}^{1}[1]^{*} \\
\mathrm{Y}_{\mathrm{I}}[1]=\frac{\mathrm{H}^{1,2}[0]^{*}}{\|\mathrm{H}(0)\|} \mathrm{Y}_{\mathrm{I}}^{1}[0]-\frac{\mathrm{H}^{1,1}[0]}{\|\mathrm{H}(0)\|} \mathrm{Y}_{\mathrm{I}}^{1}[1]^{*} \\
\mathrm{~W}_{\mathrm{I}}[0]=\frac{\mathrm{H}^{1,1}[0]^{*}}{\|\mathrm{H}(0)\|} \mathrm{W}_{\mathrm{I}}^{1}[0]+\frac{\mathrm{H}^{1,2}[0]}{\|\mathrm{H}(0)\|} \mathrm{W}_{\mathrm{I}}^{1}[1]^{*} \\
\mathrm{~W}_{\mathrm{I}}[1]=\frac{\mathrm{H}^{1,2}[0]^{*}}{\|\mathrm{H}(0)\|} \mathrm{W}_{\mathrm{I}}^{1}[0]-\frac{\mathrm{H}^{1,1}[0]}{\|\mathrm{H}(0)\|} \mathrm{W}_{\mathrm{I}}^{1}[1]^{*}
\end{gathered}
$$

A simple zero forcing equalizer can be used to detect the transmitted coded OFDM symbols from (20)

$$
\mathrm{X}_{\mathrm{I}}[0] \square \frac{\mathrm{Y}[0]}{\|\mathrm{H}[0]\|}
$$




$$
\mathrm{X}_{\mathrm{I}}[1] \square \frac{\mathrm{Y}[1]}{\|\mathrm{H}[0]\|}
$$

\section{ADAPTIVE TRANSMIT DIVERSITY SELECTION}

The Adaptive transmit Diversity Selection (ATDS) adaptively selects a diversity scheme based on the current channel condition. The receiver estimates the channel and determines whether it is flat fading or frequency fading. Based on this information, the diversity scheme determination is done at the receiver and the channel index $(\mathrm{CI}=0$ for flat fading and $\mathrm{CI}=1$ for frequency fading) is fed back to the transmitter side.

The ATDS block at the transmitter assigns the diversity scheme using the received channel index $(\mathrm{CI})$. For $\mathrm{CI}=0$, the ATDS assigns Path 0 that provide time and space diversity using Alamouti STBC coding. The OFDM signals at the output of the IFFT block undergoes STBC encoding (see section II) and is transmitted through two transmitting antennas to obtain spatial diversity. On the other hand, for $\mathrm{CI}=1$, Path 1 is assigned which give frequency diversity. The M-QAM modulated symbols are SFBC encoded (section III) and then produce two separate OFDM symbols that are transmitted through two transmitted antennas just like Path 1 in order to achieve spatial diversity.

At the receiver side decoding is done in the same way based on CI. The Diversity Determination block chooses the path in the receiver side. Path 0 provides STBC decoding

Table 1: The Proposed ATDS Algorithm

\section{Algorithm:}

1. Estimate Channel State Information (CSI) at the receiver.

2. Based on CSI, determine the type of the channel If $\left[\boldsymbol{T}_{\mathbf{s}}\right.$ (Symbol duration) $\boldsymbol{D} \boldsymbol{\sigma}_{\boldsymbol{n}}$ (rms delay spread)] or $\boldsymbol{B}_{\boldsymbol{s}}$ (Bandwidth of signal) $\mathbf{D} \boldsymbol{B}_{\boldsymbol{c}}$ (Coherence bandwidth of channel)\}

The channel is flat fading.

Else

The channel is frequency selective fading.

3. Assign Channel Index ' $\mathrm{CI}=0$ ' for flat fading charnel and ' $\mathrm{CI}=1$ ' for frequency selective fading channel.

4. Feed back the corresponding channel indices to the ATDS at the transmitter.

5. The ATDS system works as follows

If $\mathrm{CI}=0$

Select Path 0 and Connect to the STBC encoder

Else

Select Path 1 and Connect to the SFBC encoder

6. For decoding, at the receiver

If $\mathrm{CI}=0$

Select path 0 and connect to STBC decoder Else
Whereas Path 1 provides SFBC decoding. Unlike the conventional diversity techniques which could follow both time or frequency diversity, the ATDS adaptively selects the diversity scheme and hence uses the full benefits time, frequency and spatial diversity techniques and thus improves the overall system performance.

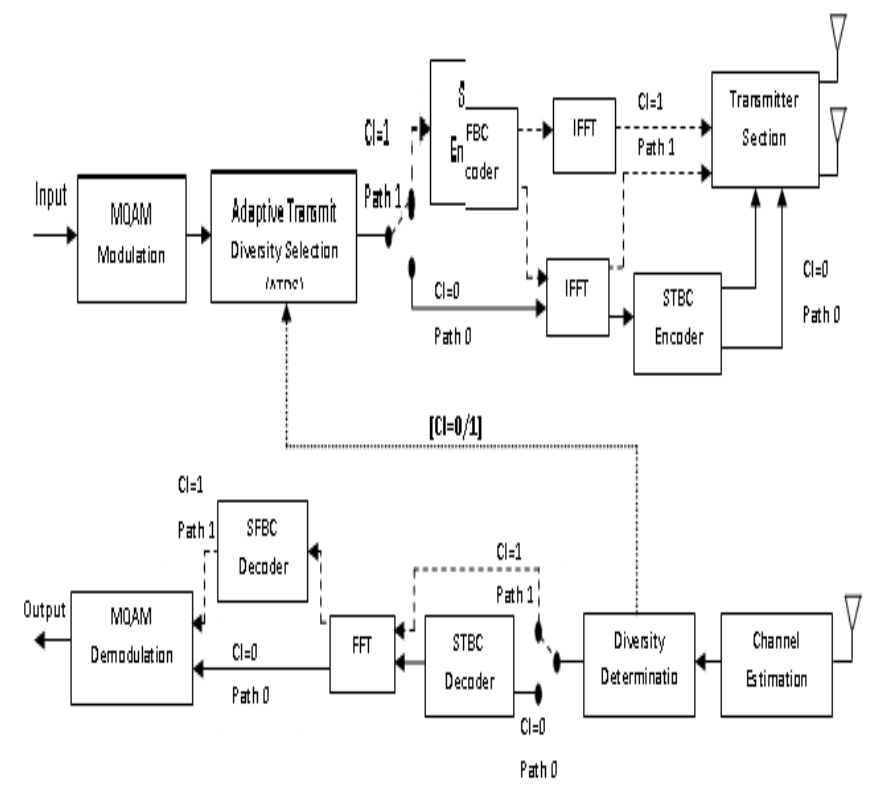

Fig 2: ATDS block diagram

\section{SIMULATION RESULTS}

To test the performance of proposed ATDS scheme we take the following parameters. The number of Subcarriers in one OFDM symbol is 64 and Bandwidth (B) is assumed to be $5 \mathrm{MHz}$, number of transmitting antennas $\left(\mathrm{N}_{\mathrm{T}}\right)$ are 2 and number of receiving antenna $\left(N_{R}\right)$ is 1 , the code rate $\left(R_{C}\right)$ is one and the target BER is $10^{-4}$. The performance of the proposed scheme is evaluated for 100 channels and the average BER and SE results are compared with the conventional system. The fading process is assumed to be stationary and the channel is assumed to be static during one OFDM block length.

The instantaneous BER of $\mathrm{m}^{\text {th }}$ subcarrier in $\mathrm{I}^{\text {th }}$ OFDM symbol with M-QAM is given as

$$
\mathrm{BER}_{\mathrm{I}}(\mathrm{m})=0.2 \exp \left\{\frac{-1.6 \gamma_{\mathrm{S}}}{2\left(2^{\mathrm{b}(\mathrm{m})}-1\right)}\left(\left|\mathrm{H}^{1,1}[\mathrm{~m}]\right|^{2}+\left|\mathrm{H}^{1,2}[\mathrm{~m}]\right|^{2}\right)\right\}
$$

where, $\gamma_{\mathrm{S}}=\mathrm{E}_{\mathrm{S}} / \mathrm{N}_{0}$ and $\mathrm{E}_{\mathrm{S}}$ is the symbol energy at the transmitter and $\mathrm{N}_{0} / 2$ is the variance of Additive White Gaussian Noise (AWGN), b(m) is the number of bits loaded on the $\mathrm{m}^{\text {th }}$ subcarrier and $\mathrm{H}^{1,1}[\mathrm{~m}], \mathrm{H}^{1,2}[\mathrm{~m}]$ are the $\mathrm{m}^{\text {th }}$ sub channel amplitudes of transmitter antennas to the receiver antenna[4]. 


$$
\mathrm{BER}=\frac{1}{\mathrm{~L}} \sum_{\mathrm{m}=0}^{\mathrm{L}-1} \mathrm{BER}(\mathrm{m})
$$

Where L represents the total number of subcarriers in one OFDM symbol[3, 4].

The Average SE of the $\mathrm{I}^{\text {th }}$ OFDM symbol is given as

$$
\mathrm{SE}_{\mathrm{I}}=\frac{1}{\mathrm{~B}\left(\mathrm{~T}_{\mathrm{u}}+\mathrm{T}_{\mathrm{g}}\right)} \sum_{\mathrm{m}=0}^{\mathrm{L}-1} \mathrm{~b}(\mathrm{~m})\left(1-\mathrm{BER}_{\mathrm{I}}(\mathrm{m})\right)
$$

Where $T_{u}$ is the useful symbol duration and $T_{g}$ is the guard interval $[4,5]$.

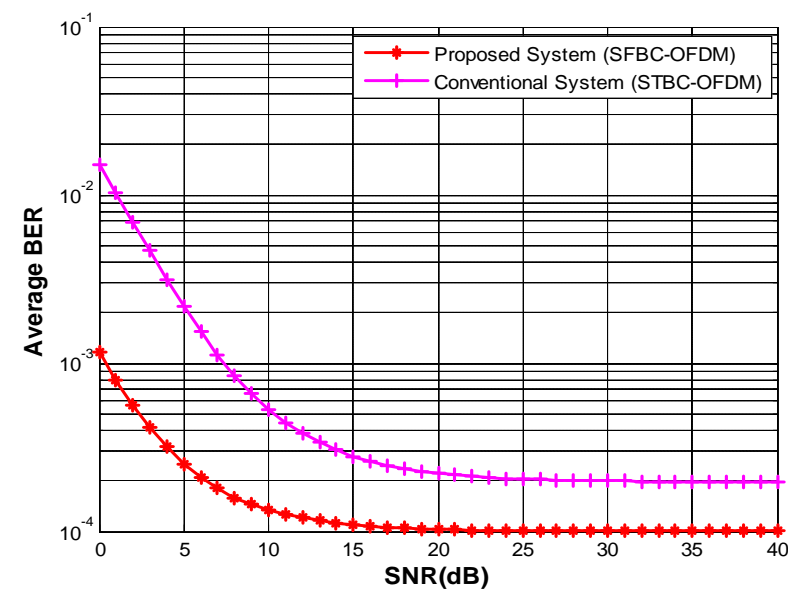

Fig 3 Average BER comparison of proposed scheme and conventional STBC-OFDM over frequency selective fading channel.

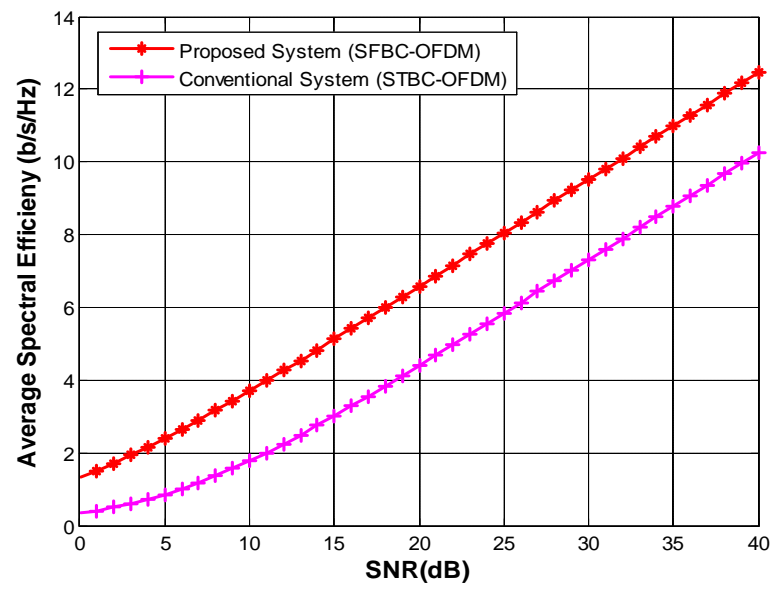

Fig 4 Average Spectral Efficiency comparison of Proposed Scheme and Conventional STBC-OFDM over frequency selective fading channel.
In the frequency selective fading channel multiple versions of the faded transmitted signal delayed in time are received and it induces inter symbol interference (ISI). A four tap channel is considered for the analysis.

In Figure 3, the average BER values of the proposed scheme and conventional STBC-OFDM system over frequency selective fading channel are calculated with equation (24) by varying the SNR values from 0 to $40 \mathrm{~dB}$. For the proposed scheme (SFBC-OFDM) the average BER value at OdB SNR is $10^{-3}$ but this BER value is achieved at $7 \mathrm{~dB}$ SNR in case of conventional STBC-OFDM, i.e., the proposed scheme gains $7 \mathrm{~dB}$ over frequency selective fading channel.

Figure 4 shows the spectral efficiency comparison of proposed scheme and conventional scheme over frequency selective fading channel. The SE values are calculated by equation (25). For the proposed scheme (SFBC-OFDM) the average SE value at $12 \mathrm{~dB}$ SNR is $4 \mathrm{bits} / \mathrm{Hz}$ but in case of conventional STBCOFDM the value is $2 \mathrm{bits} / \mathrm{Hz}$. So the SFBC-OFDM over frequency selective fading channel provides high SE compared to the STBC-OFDM.

In flat fading channel the spectral characteristics of the transmitted signal are maintained at the receiver but the strength of the received signal varies with time due to fluctuations in the gain of the channel caused by multipath and for analysis of this a single tap channel is considered.

In Figure 5 the average BER values of the proposed scheme and conventional SFBC-OFDM system over flat fading channel are calculated with equation (24) by varying the SNR. For the proposed scheme the average BER value at OdB SNR is $0.07 \times 10^{-3}$ but this same BER value is achieved at $14 \mathrm{~dB}$ SNR in case of SFBC-OFDM, which implies that the proposed scheme gains $14 \mathrm{~dB}$ over flat fading channel.

Figure 6 shows the spectral efficiency comparison of proposed scheme and conventional scheme over flat fading channel. 


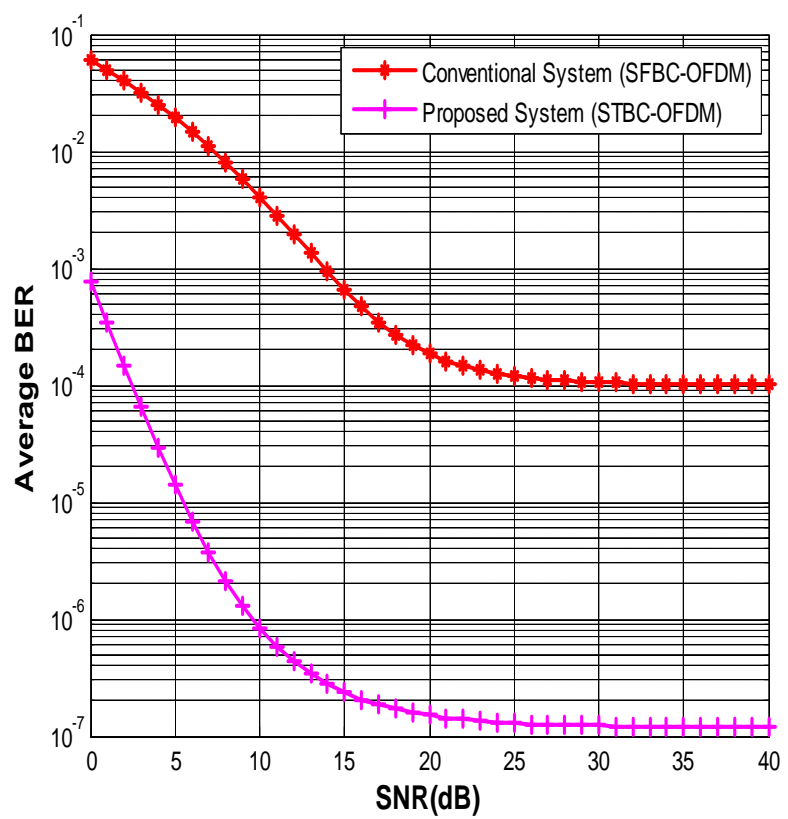

Fig 5 Average BER comparison of proposed scheme and conventional SFBC-OFDM over flat fading channel

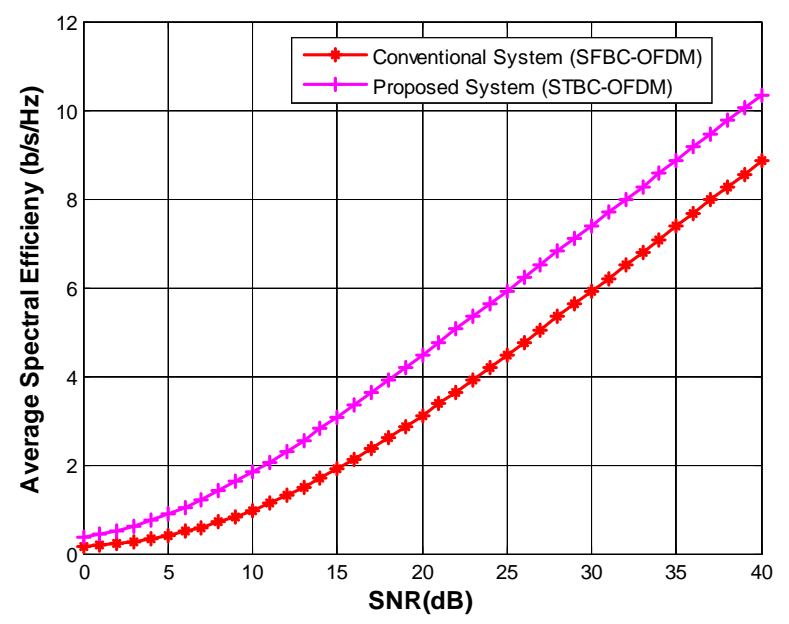

Fig 6 Average Spectral Efficiency comparison of Proposed Scheme and Conventional SFBC-OFDM over flat fading channel.

The SE values are calculated by equation (25). For the proposed scheme (STBC-OFDM) the average SE value at $12 \mathrm{~dB}$ SNR is 2bits/Hz but in case of conventional SFBC-OFDM the value is $1 \mathrm{bits} / \mathrm{Hz}$. So the STBC-OFDM over flat fading channel provides high SE compared to the SFBC-OFDM. From the results, it can be seen that the proposed ATDS scheme greatly improves the performance of a system by selecting the transmission scheme based on the present channel condition.

\section{CONCLUSIONS}

An adaptive transmit diversity selection (ATDS) scheme is proposed in this paper. The proposed scheme greatly improves the performance of a system in terms of Spectral Efficiency(SE) and quality by using the benefits of STBC-OFDM for flat fading channel and SFBC-OFDM for frequency selective fading channel as compared to a conventional system where either STBC-OFDM or SFBC-OFDM are used for both flat fading and frequency selective fading channels. Simulation results shows that in flat fading channel the proposed scheme (using STBC-OFDM) gains $14 \mathrm{~dB}$ SNR compared to SFBCOFDM system for getting $0.07 \times 10^{-3} \mathrm{BER}$ and $\mathrm{SE}$ is $2 \mathrm{bits} / \mathrm{Hz}$ rather than $1 \mathrm{bits} / \mathrm{Hz}$ for conventional system at $12 \mathrm{~dB}$ SNR. In frequency selective fading channel the proposed scheme gains $7 \mathrm{~dB}$ SNR compared to STBC-OFDM for getting $10^{-3}$ BER and $\mathrm{SE}$ is $4 \mathrm{bits} / \mathrm{Hz}$ rather than $2 \mathrm{bits} / \mathrm{Hz}$ for STBC-OFDM at $12 \mathrm{~dB}$ SNR.

\section{REFERENCES}

[1] Theodore S Rappaport, 2002, Wireless Communications Principles and Practice, Pearson Education Inc, India.

[2] Ramjee Prasad, 2004, OFDM for Wireless Communication Systems, Artech House, Inc. Boston, London.

[3] Yong Soo Cho, Jaekwon Kim, Won Young Yang and Chung G. Kang, MIMO-OFDM Wireless Communications with Matlab, John Wiley \& Sons Pvt. Ltd, Asia, 2010.

[4] Mohammad Torabi, "Antenna selection for MIMOOFDM systems," Signal Processing, vol. 88, 2008, pp. 2431-2441.

[5] S.M. Alamouti, "A simple transmit diversity technique for wireless communications," IEEE Journal on Selected Areas in Communication, vol. 16, no. 8, 1998, pp. 145114558 .

[6] Mohammad Torabi, "Adaptive modulation for spacefrequency block coded OFDM systems," International Journal of Electronics and Communications, vol. 62, no. 7, 2008, pp. 521-533. 